\title{
Penggunaan Metode Naive Bayes Classifier untuk Mengevaluasi Kinerja Akademik Mahasiswa di Perguruan Tinggi
}

\author{
Novitalia $^{1}$, Putri Dinanti Mawasgenti ${ }^{2}$, Tina Apriani ${ }^{3}$, Ahmad Prayogi $\mathrm{S}^{4}$, Aries Saifudin ${ }^{5}$ \\ Teknik Informatika, Universitas Pamulang, Tangerang Selatan, Indonesia, 15417 \\ e-mail: ${ }^{1}$ novitalia171@ gmail.com, ${ }^{2}$ putridinanti04@gmail.com, ${ }^{3}$ tapriani44@ gmail.com, \\ ${ }^{4}$ aprayogi164.com, ${ }^{5}$ aries.saifudin@ unpam.ac.id
}

Submitted Date: November $17^{\text {th }}, 2020$

Revised Date: July $06^{\text {th }}, 2021$
Reviewed Date: November 23, 2020

Accepted Date: July $07^{\text {th }}, 2021$

\begin{abstract}
Inaccuracy in selecting faculties at universities is one of the constraints experienced by students which affect academic values or student performance which affects the accuracy of student graduation, in developing a performance it is necessary to know the individual talents of the students, this is the background of the application The Naive Bayes Classifier (NBC) Algorithm method in admitting new students to find out the talents and interests of students, with the NBC method it is expected that there will be an increase in the activity of students in higher education. The research that we do focuses on evaluating the success of administering a department at a university. Our research focuses on evaluating the success of administering a department at a university using the Naive Bayes Classifier (NBC) algorithm. Because the success of student academic performance is very dependent on the level of student ability to develop the knowledge they have. So that to evaluate the performance of students, a method is needed, namely the Naive Bayes Classifier (NBC) algorithm to analyze the level of student performance. The results of this study will show which are very influential on the provisions of a classification of a student's academic performance. The results can be based on the Achievement Index (IP) so that the results obtained by the method used can be used as evaluation material for the university or related students.
\end{abstract}

Keywords: University; Student; Performance; Naive Bayes Classifier (NBC)

\begin{abstract}
Abstrak
Ketidaktepatan dalam pemiliahan fakultas di universitas adalah salah satu kendal yang dialami oleh mahasiswa yang berpengaruh terhadap nilai-nilai akdemik atau kinerja mahasiswa yang berdampak terganggunya ketepatan dalam kelulusan mahasiswa tersebut, dalam mengembangkan suatu kinerja perlu mengetahui bakat individu dari para mahasiswa, hal ini melatar belakangi penerapan metode Algoritma Naive Bayes Classifier (NBC) dalam peneriman mahasiswa baru agar mengetahui bakat dan minat dari para mahasiswa, dengan metode NBC diharapkan adanya penigkatan ektivitas dari para mahasiswa dalam perguruan tinggi. Penelitian yang kami lakukan fokus untuk mengevaluasi keberhasilan penyelenggara suatu Jurusan pada salah satu Universitas. Penelitian yang kami lakukan fokus untuk mengevaluasi keberhasilan penyelenggara suatu Jurusan pada salah satu Universitas dengan menggunakan metode Algoritma Naive Bayes Classifier (NBC). Karena keberhasilan kinerja akademik mahasiswa sangat bergantung pada tingkat kemampuan mahasiswa dalam mengembangkan ilmu yang dimiliki. Sehingga untuk mengevaluasi kinerja dari mahasiswa diperlukan sebuah metode yakni Algoritma Naive Bayes Classifier (NBC) untuk menganalisa seberapa besarkah tingkat kinerja mahasiswa. Hasil dari penelitian ini akan menunjukkan mana saja yang sangat berpengaruh terhadap ketentuan suatu klasifikasi kinerja akademik seorang mahasiswa. Adapun hasilnya dapat berdasarkan Index Prestasi (IP) sehingga hasil yang diperoleh dengan metode yang digunakan dapat menjadikan bahan evaluasi terhadap pihak universitas ataupun mahasiswa terkait.
\end{abstract}

Kata Kunci: Universitas; Mahasiswa; Kinerja; Naive Bayes Classifier (NBC) 


\section{Pendahuluan}

Dalam dunia pendidikan, terutama dalam lingkup perguruan tinggi, sering kali mahasiswa dituntut memiliki kinerja akademik yang maksimal sebagai tolak ukur dalam melakukan evaluasi. Sedangkan aspek penting dalam menentukan kinerja akademik mahasiswa berkaitan dengan ketrampilan mahasiswa untuk mengembangkan ilmu. Pada saat ini, pengembangan teknologi sangatlah pesat sehingga memudahkan mahasiswa dan pengajar dalam mengakses ilmu dan informasi.

Dari beberapa penelitian sebelumnya, menunjukan bahwa untuk mencapai kesuksesan akademik atau untuk meningkatkan prestasi mahasiswa sangat diperlukan mindset untuk berkembang dan percaya bahwa kecerdasan dapat tumbuh melalu kerja keras, pengalaman dan dorongan semangat dari orang lain. Salah satunya perlunya Analisa untuk mengevaluasi bagaimana kinerja akademik mahasiswa agar mahasiswa selalu termotivasi agar selalu meningkatnya prestasi atau kinerja akademiknya.

Sebagai penentu keberhasilan mahasiswa dalam program studi bisa dilihat berdasarkan ketepatan dalam menyelesaikan masa studinya. Pada penelitian sebelumnya, evaluasi dilakukan menggunakan training set dan testing set pada data mahasiswa semester 6. Oleh karena itu, diperlukan sebuah metode yang efisien dengan keakuratan yang tinggi. Dalam penelitian ini, untuk mengevaluasi kinerja akademik Mahasiswa akan menggunakan metode Naive Bayes Classifier.

Beberapa metode yang pernah diterapkan masih memiliki tingkat keakurasian yang rendah (Suprianto, 2020). Sehingga di penelitian ini kami mengusulkan untuk menggunakan metode Naive Bayes Classifier untuk mengevaluasi proses kinerja akademik pada mahasiswa di Perguruan Tinggi. Pada penelitian sebelumnya yang menggunakan metode algoritma c4.5 memperoleh hasil yakni dengan nilai koefiesien relasi pelatihan sebesar 0,94353 sedangkan untuk nilai MSE memperoleh nilai yakni 0,016175 dan sedangkan nilai koefiesien relasi pengujian adalah 0,56071 dan nilai MSE adalah 0,12188. Sehingga dalam penelitian, ini kami menggunakan metode algoritma Naive Bayes Classifier. Selain bisa dipakai untuk data kuantitatif, algoritma Naive Bayes ini juga bisa mengolah data kualitatif, yang tidak memerlukan jumlah data yang banyak (Astuti, Sudibyo, Kurniawan, \& Rahayu, 2018). Sehingga kami bisa menggunakan beberapa data sample yang akan kita gunakan untuk melakukan penelitian ini.
Algoritma Naive Bayes Classifier adalah algoritma klasifikasi yang berdasarkan pedoman berdasarkan teorema Bayes. Ciri khas dari algoritma Naive Bayes ini adalah pengasumsian yang kuat terhadap independensi terhadap masing masing kejadian (Ridwan, Suyono, \& Sarosa, 2013). Algoritma Naive Bayes ini bekerja dengan baik jika dibandingkan dengan algoritma classifier yang lain.

\section{Metodologi}

Metode yang digunakan dalam penelitian, yaitu menerapkan data mining dan pengolahan melalui proses klasifikasi dengan Algoritma Naive Bayes Classifier (Mustafa \& Simpen, 2019).

\subsection{Data Mining}

Data mining suatu proses penambangan data dengan menggunakan teknologi pengenalan pola (pattern recognition), machine learning serta teknik matematika, statistic dan database (Rohman, 2015). Tujuan pemrosesan data mining yakni untuk menentukan hubungan antar pola yang mendapatkan indikasi yang bermanfaat. Maka dalam penelitian ini, kami menerapkan metode klasifikasi karena metode ini bisa mengelompokkan data berdasarkan keterkaitan data yang sudah ada serta bisa mengatasi masalah pada data yang besar.

Tahap dalam pengolahan data mining, yaitu:

1. Penghapusan data

Penghapusan / pembersihan pada data yang mengganggu atau data yang tidak penting serta memperbaharui data yang hilang.

2. Penggabungan data

Penggabungan data dari beberapa sumber yang sudah ada, digunakan dalam pemrosesan data mining, disimpan disuatu berkas, dan terpisah dari operasional dalam basis data.

3. Pemilihan data

Pencarian selanjutnya dengan memilih data, data yang sudah relevan akan dipilih dan dikumpulkan kembali

4. Transformasi data

Tahap transformasi adalah tahap setelah data sudah dipilih. Sehingga proses coding ini merupakan proses yang sangat bergantung pada jenis dan pola informasi yang dicari dalam basis data

5. Evaluasi pola

Dari pola-pola yang dikumpulkan, akan dipilih pola yang menarik. Pola tersebut yang akan diambil. 
6. Penyajian pola

Setelah diambil pola yang menarik, pola yang diambil tersebut kemudian akan divisualisasikan ke pengguna.

\subsection{Algoritma Naïve Bayes Classifier (NBC)}

Algoritma naive bayes classifier adalah suatu proses pengklasifikasian dimana algoritma ini mengasumsikan atribut objek secara independen (Nasution, Djahara, \& Zamsuri, 2015). Dalam penelitian ini, Naive Bayes Classifier berperan sangat penting. karena metode di dalam algoritma ini memiliki keakuratan yang sangat baik dalam pengklasifikasian (Mulyati, Yulianti, \& Saifudin, 2017). Algoritma ini juga hanya membutuhkan jumlah data training yang lebih sedikit.

Kelebihan lain yang didapat menggunakan algoritma ini adalah misalnya kita menggunakan dalam bahasa pemrograman codenya relatif sangat sederhana dan mampu digunakan untuk menyelesaikan masalah klasifikasi dan masalah biner atau multiclass. tetapi walaupun mempunyai kelebihan algoritma ini mempunyai kekurangan dalam membuat suatu keputusan, diperlukannya sebuah riset awal atau dengan riset masa sebelumnya. Keberhasilan yang dihasilkan sangat bergantung pada riset awal tersebut. Banyak celah yang bisa mengurangi efektifitas yang dirancang hanya untuk mendeteksi sebuah kata-kata saja, tidak bisa menghasilkan berupa gambar.

\section{Hasil dan Pembahasan}

Dalam tahap penerapan model ini akan menerapkan model yang akan menghasilkan model terbaik dari model sebelumnya. Dalam penelitian ini, kami mengumpulkan beberapa sample dari 380 mahasiswa berdasarkan IPK.

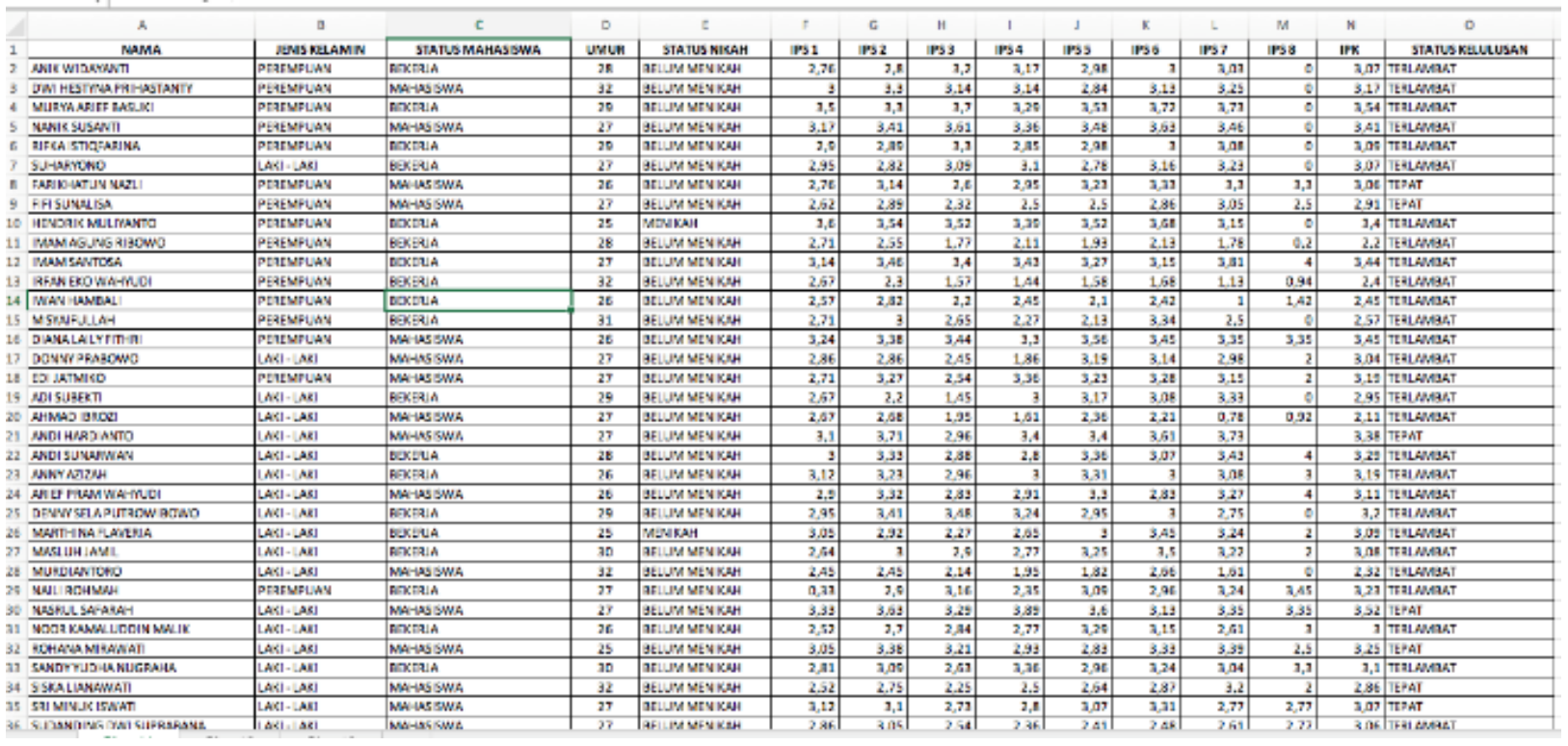

Gambar 1 Data mahasiswa

Berikut tahapan metode algoritma Naive Bayes Classifier dengan menggunakan software rapid miner.

\subsection{Penghapusan data}

Penghapusan data ini merupakan suatu proses untuk menghilangkan data yang mengganggu (Rismayanti, 2016) (Yasmiati,
Wahyudi, \& Susilo, 2017). Proses awal ini sangat berpengaruh pada performa teknik data mining (Rifqo \& Wijaya, 2017). Data yang tidak relevan ini misalnya data yang hilang, data yang salah ketik dan data yang tidak valid (Mandias, 2015). Di sini, kami mengambil sample dari dataset kelulusan mahasiswa dari 380 mahasiswa. 


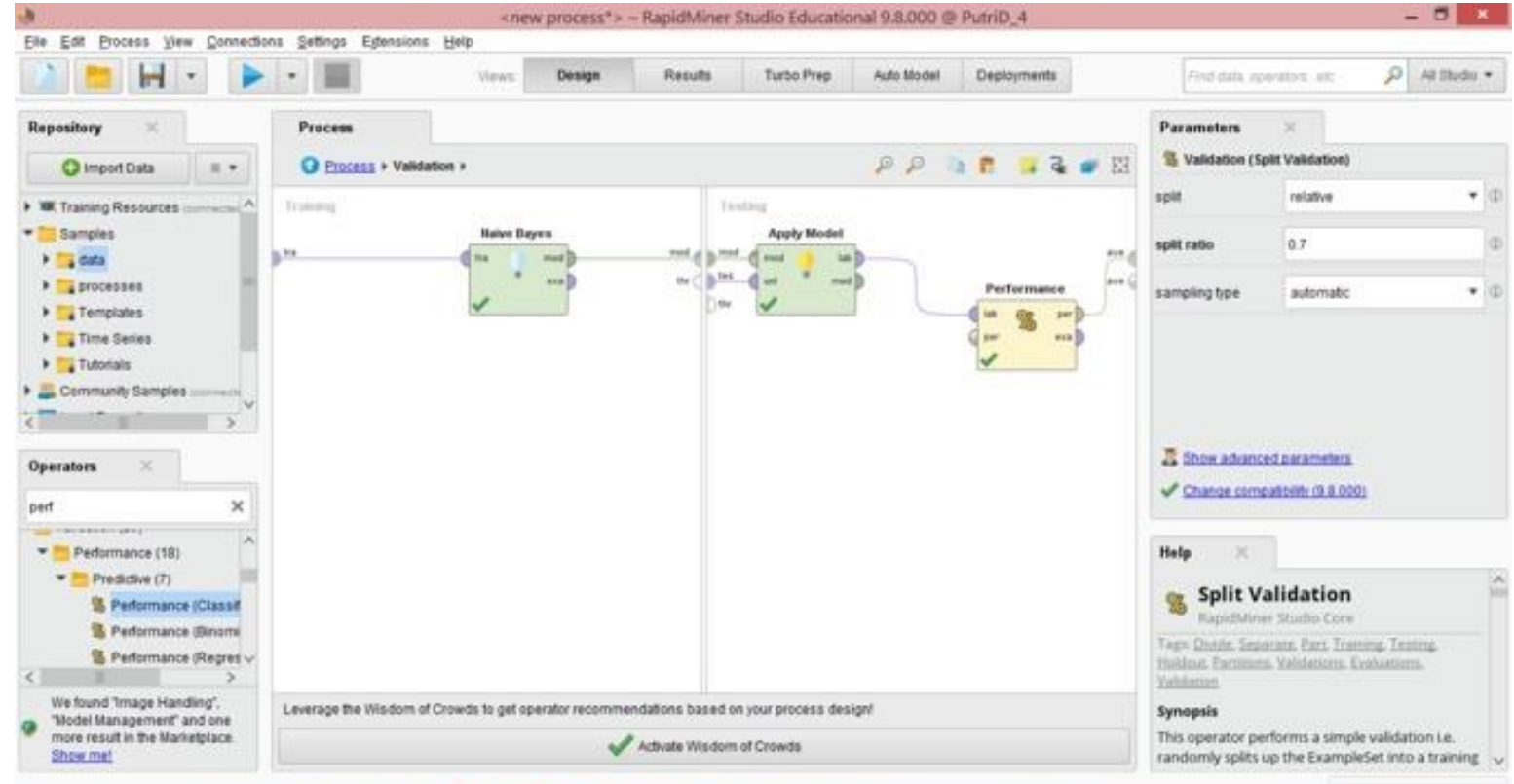

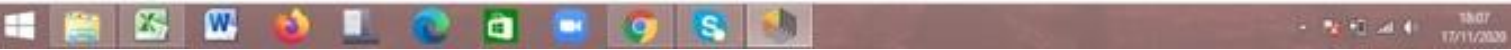

Gambar 2 Susunan model

\subsection{Penggabungan data}

Tahap berikutnya adalah tahap untuk ada. Berikut penggabungan data dari beberapa menggabungkan data dari beberapa sumber yang

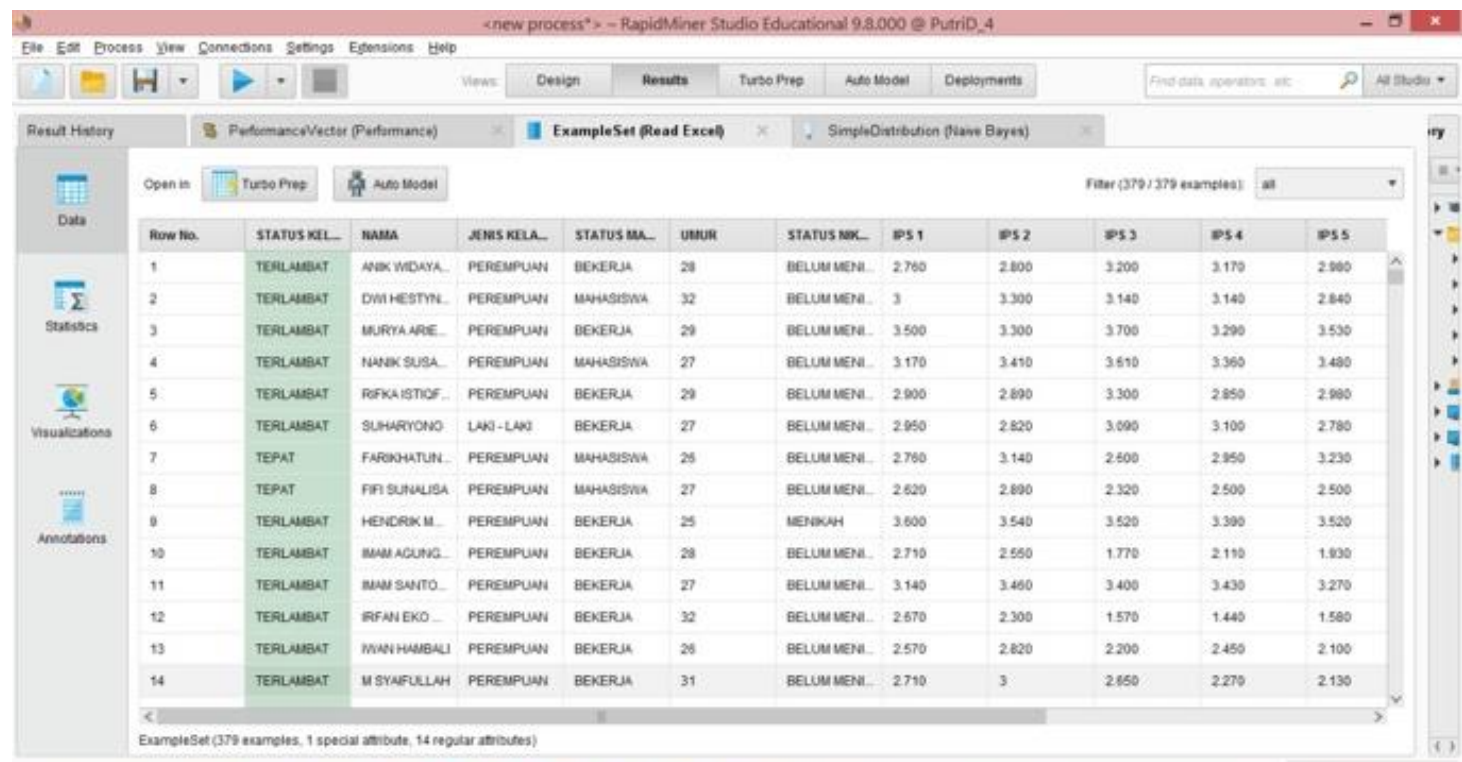

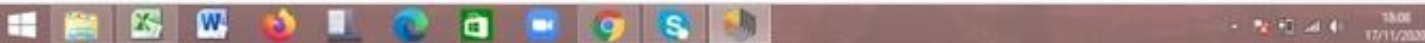

Gambar 3 Hasil pembacaan data

\subsection{Pemilihan data}

Langkah selanjutnya adalah pemilihan data yang sudah relevan dan akan dijadikan satu kembali. Dalam uji data ini didapatkan nilai akurasi sebesar $79,82 \%$. Untuk status kelulusan terlambat sebesar $76,00 \%$ dan status kelulusan tepat sebesar $82,81 \%$. 


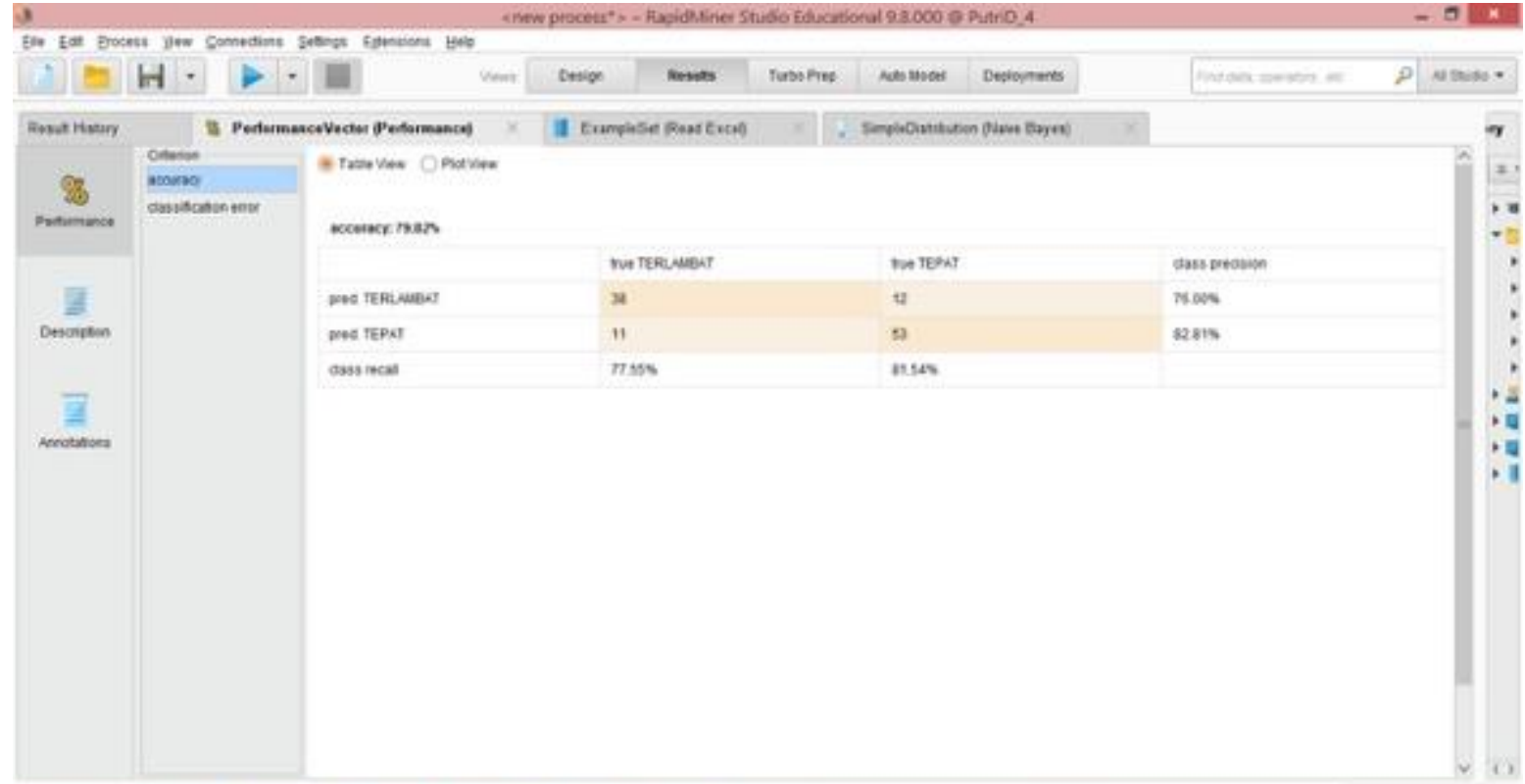

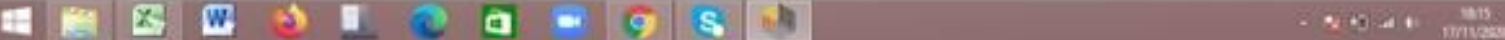

Gambar 4 Akurasi model

Sedangkan untuk uji klasifikasi nilai errornya sebesar $76,00 \%$ dan status kelulusan tepat sebesar sebesar 20,18\%. Untuk status kelulusan terlambat $82,81 \%$.

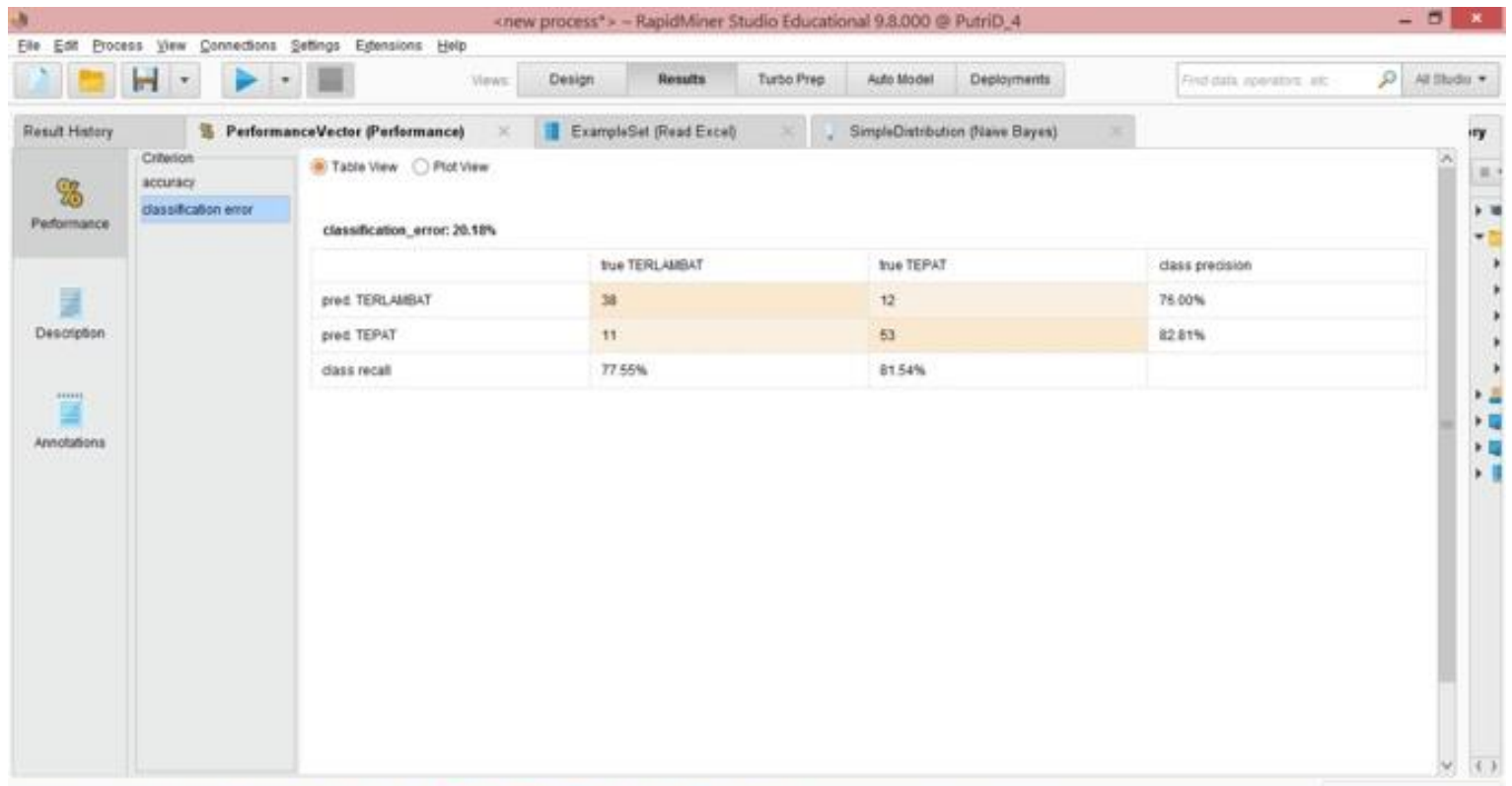

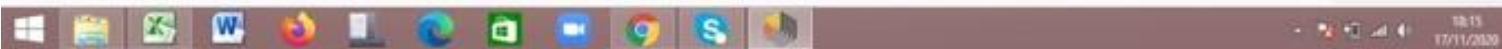

Gambar 5 Nilai kesalahan klasifikasi

\subsection{Transformasi data}

Proses transformasi pada data kelulusan mahasiswa yang sudah dipilih yang akan digunakan untuk proses data mining ini akan mengubah nilai dari atribut yang diubah menjadi bentuk diskrit menggunakan algoritma Naïve Bayes Classifier. Untuk mahasiswa yang berstatus bekerja, status kelulusan terlambatnya sebesar 0,75 lalu untuk status kelulusan tepatnya sebesar 0,00. Sedangkan mahasiswa dengan status mahasiswa, status kelulusan terlambatnya sebesar 0,20 dan status kelulusan tepatnya sebesar 0,95 . 


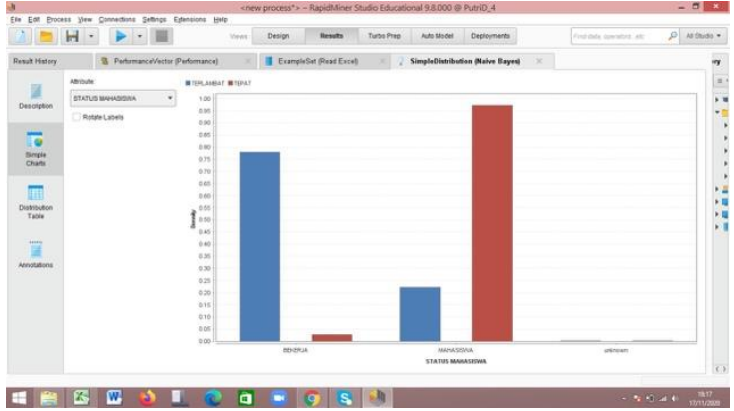

Gambar 6 Grafik kinerja model

\subsection{Evaluasi pola}

Dari beberapa pola yang sudah dikumpulkan, maka tahap selanjutnya adalah mengevaluasi pola untuk menyajikan pola yang paling menarik. Berikut beberapa pola yang sudah diambil.

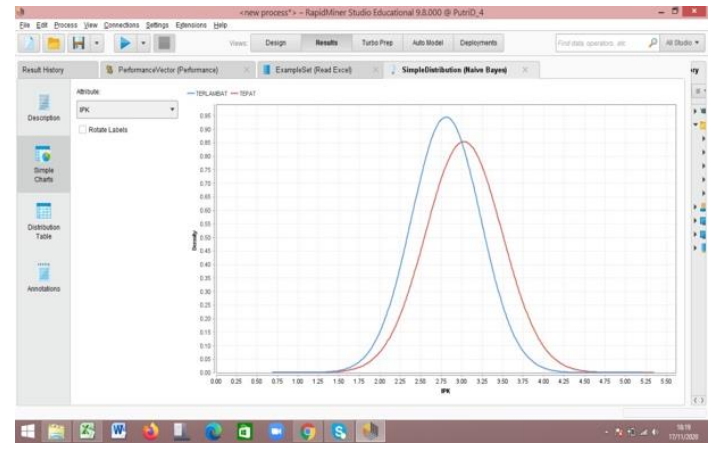

Gambar 7 Grafik pola model

\section{Kesimpulan}

Berdasarkan hasil penelitian yang telah kami dilakukan, berikut kesimpulannya:

1. Penerapan suatu metode Naive Bayes Classifier untuk maksimal tolak ukur dalam melakukan suatu evaluasi, dunia pendidikan, terutama dalam lingkup perguruan tinggi.

2. Metode Naive Bayes Classifier dapat diimplementasikan sebagai penentu keberhasilan mahasiswa dalam program studi untuk ketepatan dalam menyelesaikan masa studinya.

\section{Saran}

Berdasarkan hasil penelitian yang kami lakukan, kami mengharapkan penelitian selanjutnya mengembangkan hal-hal berikut ini:

1. Keakuratan metode algoritma naive bayes classifier ini sesuai atau berdasarkan dengan jumlah. Sehingga disarankan untuk adanya pengembangan pada sistem.

2. Untuk mengetahui cara evaluasi peningkatan dalam dunia pendidikan terutama dalam perguruan tinggi, diperlukan adanya penelitian lanjutan dalam jangka waktu tertentu.

\section{Referensi}

Astuti, Y. P., Sudibyo, U., Kurniawan, A. W., \& Rahayu, Y. (2018). Algoritma Naive Bayes dengan fitur seleksi untuk mengetahui hubungan variabel nilai dan latar belakang pendidikan. Simetris: Jurnal Teknik Mesin, Elektro dan Ilmu Komputer, 9(1), 597-602. doi:10.24176/simet.v9i1.2016

Mandias, G. F. (2015). Penerapan Data Mining Untuk Evaluasi Kinerja Akademik Mahasiswa Di Universitas Klabat Dengan Metode Klasifikasi. Proceedings Konferensi Nasional Sistem dan Informatika (KNS\&I) (pp. 351-354). Denpasar: STMIK STIKOM Bali.

Mulyati, S., Yulianti, Y., \& Saifudin, A. (2017). Penerapan Resampling dan Adaboost untuk Penanganan Masalah Ketidakseimbangan Kelas Berbasis Naïve Bayes pada Prediksi Churn Pelanggan. Jurnal Informatika Universitas Pamulang, 2(4), 190-199. doi:10.32493/informatika.v2i4.1440

Mustafa, M. S., \& Simpen, I. W. (2019). Evaluasi Kinerja Akademik Mahasiswa Menggunakan Algoritma Naive Bayes Classifier (Studi Kasus STMIK Dipanegara). JUSITI (Jurnal Sistem Informasi dan Teknologi Informasi), 193-202.

Nasution, N., Djahara, K., \& Zamsuri, A. (2015). Evaluasi Kinerja Akademik Mahasiswa Menggunakan Algoritma Naïve Bayes (Studi Kasus: Fasilkom Unilak). Digital Zone: Jurnal Teknologi Informasi dan Komunikasi, 6(2), 111. doi:10.31849/digitalzone.v6i2.91

Ridwan, M., Suyono, H., \& Sarosa, M. (2013). Penerapan Data Mining Untuk Evaluasi Kinerja Akademik Mahasiswa Menggunakan Algoritma Naive Bayes Classifier. Jurnal EECCIS, 7(1), 59-64.

Rifqo, M. H., \& Wijaya, A. (2017). Implementasi Algoritma Naiva Bayes dalam Penentuan Pemberian Kredit. Jurnal Pseudocode, 4(2), 120-128. doi:10.33369/pseudocode.4.2.120128

Rismayanti. (2016). Implementasi algoritma C4.5 untuk menentukan penerima beasiswa di STT Harapan Medan.

Rohman, A. (2015). Model Algoritma K-Nearest Neighbor (K-NN) untuk prediksi kelulusan mahasiswa. Neo Teknika: Jurnal Ilmiah Teknologi, $\quad 1(1), \quad 1-9$. doi:10.37760/neoteknika.v1i1.350

Suprianto, S. (2020). Implementasi Algoritma Naive Bayes Untuk Menentukan Lokasi Strategis Dalam Membuka Usaha Menengah Ke Bawah di Kota Medan (Studi Kasus: Disperindag Kota Medan). Jurnal Sistem Komputer dan 
Informatika (JSON), 1(2), 125-130. doi:10.30865/json.v1i2.1939

Yasmiati, Y., Wahyudi, W., \& Susilo, A. (2017). Pengembangan Aplikasi Data Mining dengan Algoritma c4.5 dan apriori di fakultas Teknologi Informatika Universitas Respati
Indonesia. Jurnal Teknologi, 9(1), 31-41. doi:10.24853/jurtek.9.1.31-41 